(MMR). The relevance of this research extends well beyond the particular circumstances and region studied.

The context was an outbreak in 1998 of public concern in Britain that the MMR vaccination might lead to autism in young children. The worries, which were stimulated by some scientists, proliferated and persisted despite increasingly robust reassurances from the government and clinicians that there was no epidemiological evidence for such a link.

The study of parents' responses provides a vivid demonstration of how people outside the relevant research communities develop their own knowledge and interpretation of the literature, and how the Internet allows this 'lay expertise' to be shared within a climate of shared perceptions of risk (see the unrefereed report MMR Mobilisation: Citizens and Science in a British Vaccine Controversy; www.ids.ac.uk/ids/bookshop/wp/wp247.pdf). For example, one parent, David Thrower, compiled his own review of the literature (www.whale.to/a/thrower04.html), and several websites promptly supplied hostile responses to every government reassurance.

Leach's research highlights the influences on such resistance. Confounding stereotypes, the parents ranged across the social classes and in many cases displayed a sophisticated understanding of the issues. Surveys of parents on both sides of the debate revealed a significant association of those opposed to MMR with family histories of illness and with an interest in alternative medicines and homeopathy. There was a strong sense of responsibility among mothers of both persuasions about decisions over whether to have their children vaccinated, with concerns about the social value of vaccination in terms of herd immunity being given much lower priority.

The study's account of these developments is only partial, however. Close reading reveals an undercurrent of sympathy towards the parents and relatively cursory attention to attempts by the govern- ment and others to survey the evidence and respond to the parents' concerns. But the research is focused on the parents by definition, and provides an important starting point in trying to understand the various forces at work in a classic stand-off between citizens and science-based government advice.

Leach's work points to a conflict between concerns about MMR based on individual clinical studies versus government reassurances based on epidemiology. Soon after the publication of Leach's report, a meta-analysis of the literature on MMR by the prestigious Cochrane Collaboration, while highlighting shortcomings in many studies, concluded that there was a lack of evidence to support a link with autism (www.mrw.interscience.wiley.com/cochrane/dsysrev/ artides/CD004407/pdf_fs.html). A visit to one of the websites opposed to the MMR vaccine (www.jabs.org.uk) reveals a critique of the meta-analysis that attempts to undermine its reassurance. And so the debate continues. Meanwhile, the up-
"There is a strong case for a well-resourced independent agency that commands the trust of both the government and the public." take of MMR vaccine, which fell significantly, is recovering.

In most countries, the departments of health are responsible for advising citizens on health matters. They, perhaps, have the most to gain from in-depth studies of public responses, while scientific academies may also find such accounts of alternative science sobering. But as happened with MMR, some key sectors of the public can lose faith in both the government and scientists. Thus there is a strong case for a well-resourced independent national agency that commands the trust of both the government and the public in matters of health protection and is empowered to take responsibility for mediating in such debates.

\section{Sound science}

\section{Audio files downloaded from the Internet can enrich scientific communication.}

T hanks in large part to the ubiquity of Apple's iPod, the Internet is now host to a newkind of audio transmission - the podcast. Last September, we quietly introduced the Nature Podcast, which each week highlights a selection of papers and news features from the latest issue, with interviews of authors and their peers. In this way we let scientists explain their results to a wide audience, in their own words. Their input is augmented by comment and analysis from our own editors and journalists.

For the uninitiated, a podcast - a nifty contraction of iPod and broadcast - involves the automatic downloading of an audio show via an Internet content-distribution mechanism known as an RSS feed. Listeners just enter the address of a show in the podcast section of Apple's iTunes software. Each time a show is released, it is downloaded straight to their computer.

The podcast has come to the fore because of the iPod's success and the convenience of hearing an audio item at a time that suits the listener, rather than when radio schedules dictate. Podcast fans can now catch up on Nature when setting up their experiments, sitting in traffic or walking the dog. They can also enjoy a growing array of other content, ranging from podcast museum tours to directors' commentaries that augment television programmes.

Nature is immensely pleased that, as we go to press, our show sits unassumingly between a Bob Dylan commentary and the CNN news update in iTunes' top 100 podcast chart. This demonstrates how the technology is helping the work that we publish to reach a wider public. There are other science podcasts too, including contributions from the New England Journal of Medicine and from NASA, as well as podcast versions of established radio shows, such as Science Friday. The presence of science podcasts in the charts suggests that there is plenty of interest in their subject matter.

After experimenting successfully with the Nature Podcast over the past few months, we are now establishing it as a more permanent component of our publication. We warmly invite readers to listen to the show now at www.nature.com/nature/podcast and then take part in our listener survey to let us know how the new venture can be further enhanced. 